\title{
THE ROUTINE TREATMENT OF GONORRHEA AND SYPHILIS
}

The methods employed in the diagnosis and treatment of gonorrhœea and syphilis are both diverse and divergent. It is, therefore, a matter of academic interest and of vital importance that we should arrive at an appreciation of the standard of procedure adopted by practitioners, whose range of experience, both quantitative and qualitative, endows their pronouncements with a substantial measure of authority. In the hope of providing our readers with information which shall be helpful and interesting we are sending out a number of Questionnaires on this subject to the Directors of many of the best known clinics both at home and abroad.

Our Interrogatory Document includes those fundamental questions about which, we believe, the keen worker in venereal diseases would naturally desire information if he, personally, were in a position to catechise the recipient of the Questionnaire.

We propose to publish one or more articles based upon the answers to our Questionnaire, in several succeeding numbers of the Journal. We would ask our readers to remember the categorical nature of the form of enquiry which we have sent out, if the articles placed before them appear to be cast in a form which is more colloquial than academic. 